\title{
Is Scoring Helpful Feedback for Writing Tasks? An Examination of Teachers' Beliefs
}

\author{
Parinda Jantori \\ King Mongkut's University of Technology Thonburi, Thailand \\ Saowaluck Tepsuriwong \\ King Mongkut's University of Technology Thonburi, Thailand \\ Pornapit Darasawang \\ King Mongkut's University of Technology Thonburi, Thailand
}

\begin{abstract}
Understanding teachers' beliefs about scoring procedures can be beneficial for educators in order to understand factors including challenges the teachers face when dealing with writing evaluation. This study investigated teachers' beliefs about scoring procedures through the narrative approach. Their stories were revealed through repertory grid interviews based on the Personal Construct Theory. The method encouraged teachers to think more critically when expressing their beliefs, so their genuine voices and experiences could be revealed. Two native and two non-native English-speaking teachers at the university level were interviewed about their methods of assigning scores when evaluating an essay. The interviews revealed that several factors, such as learning, practicality, experience, objectivity, and confidence could influence teachers' beliefs when deciding which scoring procedures to use. The challenges that educators might face when giving feedback were also discussed.
\end{abstract}

Index Terms — teachers' beliefs, scoring, repertory grid interview

\section{INTRODUCTION}

Written feedback is crucial for both teachers and students as it contributes to students' growth as writers (Mahfoodh \& Pandian, 2011). It is also a method that allows writing teachers to interact with their students, which is an important part of the learning process. Teachers may employ different forms of written feedback according to their beliefs about teaching and learning. Of all forms of written feedback, perhaps the most common form is a scoring rubric, which is used either as an element of in-class assessment, or end-of-course assessment.

The scoring rubric includes descriptors that help teachers judge students' proficiency level on their written work, given that the rubric is reliable, unbiased, valid, and with sufficient details provided for the descriptors provided (Ghalib \& Al-Hattami, 2015). Scoring is considered one of the most common procedures in evaluating students' writing, and there are several types of scoring that a teacher can choose from. The typical ones are holistic scoring, analytic scoring, or multiple trait scoring - all of which are viewed differently by teachers. Some teachers may feel comfortable using holistic scoring; some may be keen on using analytic scoring; while others may not consider scoring to be useful.

Researchers have also taken an interest in scoring rubrics. For instance, although holistic scoring has been used widely and is seen as convenient to many teachers, its value has been challenged by Hamp-Lyons (2016a, 2016b). In her editorial, "Farewell to Holistic Scoring Part 2: Why Build a House with Only One Brick?", Hamp-Lyons argues that even though holistic scoring can judge the overall quality of writing, it neglects the complex nature of the task. As such, she suggests that teachers cease using holistic scoring and switch to the multiple-trait scoring method instead. Nonetheless, some teachers continue to apply holistic scoring together with other types of scoring. The use of different types of scoring may be the result of many factors such as classroom constraints, or teachers' experience, preferences, and/or beliefs. Therefore, this study aimed to elicit teachers' beliefs about scoring methods on students' writing tasks. Understanding their beliefs may allow us to explain different scoring practices, as well as reasons for-and problems regarding-scoring methods.

\section{A. Teachers' Written Feedback and Scoring Rubric}

Teachers' written feedback could be seen as a means to provide comments on students' writing task and to help them develop their writing skills, as well as to "consolidate learning" (Hyland \& Hyland, 2006, p. 206). Teachers consider it their responsibility to provide helpful comments (Hyland, 2003), as well as evaluate how well their students have done.

Teachers' feedback can have several forms. Written commentary is one of the most common types of feedback, in which a teacher responds to students' writing by offering individualized comments, instead of evaluating their work (Hyland, 2003). As discussed earlier, scoring rubrics are also a commonly used method of giving feedback since they 
assess students' writing performance by giving numbers to reflect students' performance in their written tasks. This makes it easier for teachers to report students' grades at the end of the course.

In literature on feedback, different scholars have categorized several scoring approaches. Weigle (2002) divides them into three scoring approaches: holistic scoring, analytic scoring, and primary trait scoring. Holistic scoring refers to the approach in which teachers give a score based on the overall quality of the writing task. For analytic scoring, the writing is rated according to several aspects related to the objectives of the writing task. The scale may include features such as "content, organization, register, vocabulary, grammar, or mechanics" (Weigle, 2002, p. 114). Primary trait scoring refers to the method of evaluating a piece of writing according to a rubric specifically designed for that task. It can have several aspects according to the objectives of that writing assignment (e.g. the use of transitions, or strength of argument).

Similar to Weigle, Hyland (2003) categorizes scoring into four approaches: holistic, analytic, primary trait, and multiple trait scoring. Hyland separates trait scoring into primary trait and multiple trait scoring. For him, primary trait scoring focuses on only one aspect of evaluation, while multiple trait scoring considers writing as multifaceted, so teachers may give scores for more than one category. Hamp-Lyons (2003) categorizes scoring into three approaches: holistic scoring, multiple trait or analytic scoring, and primary trait scoring. Hamp-Lyons treats multiple trait and analytic scoring similarly, as both of them treat writing as multidimensional and sensitive to specific pieces of writing.

In this study, we categorize scoring rubrics into three approaches: holistic, analytic, and multiple trait. Following Hyland's (2003) definition of scoring approaches, holistic scoring is based on a teacher's impression of the overall quality of a writing task. It is convenient, but cannot pinpoint the specific aspects that a student may need to improve. In addition, a teacher requires experience in order to have consistency in evaluating the writing as a whole. Analytic scoring sees writing as multifaceted, but in more general aspects. It covers the general aspects of writing such as grammar, vocabulary, organization, and format. However, there are both benefits and drawbacks to analytic scoring. This type of scoring allows teachers to diagnose students' weaknesses in several aspects by using clear and understandable descriptors. However, it takes a longer time compared to providing scores based on a holistic scale. Multiple trait scoring is a specifically designed rubric for a specific writing task. This type of scoring can provide resourceful data as it can also inform students about their weaknesses in a specific writing task. Nevertheless, teachers need a considerable amount of time to apply multiple trait scoring.

With the plethora of approaches, the choice of selecting a rubric depends on teachers' purposes and it is considered to be context specific (Ghalib, \& Al-Hattami, 2015). It is also a complex process as a teacher's belief towards the use of feedback or scoring approaches may be challenged by what is deemed practical for the learning task or manageable by the students (Min, 2013; Junqueira \& Payant, 2015). When teachers make decisions in evaluating a piece of writing, there are several choices they can make in assigning scores. First, they can decide to look at writing in general aspects (e.g., grammar, vocabulary, organization, etc.) through either holistic or analytic scoring. In addition, they can evaluate the piece of writing according to the specific task objective by using either primary trait or multiple trait scoring. Finally, they can focus on the methods of providing a score to a specific piece of writing. They can give a score as an overall impression (holistic scoring), by looking at criteria that are based on general aspects of writing (analytic scoring), or based on the criteria adapted from the objectives of the specific assignment (trait scoring). Aside from the context, individual writing teachers may apply certain approaches that they think work well for them. Different approaches to scoring practices may reflect teachers' beliefs about learning and language (Hyland \& Hyland, 2006; Lee, 2008), and reflect their beliefs about what it means to be an effective teacher (Richards \& Lockhart, 1994). Hence, it is necessary to reveal teachers' beliefs which guide their scoring approach (Lee, 2008).

\section{B. Identifying Teachers' Beliefs}

The beliefs a teacher holds can influence their classroom practices (Basturkmen, Loewen, \& Ellis, 2004; Borg, 1999; Pajares, 1992; Phipps \& Borg, 2009; Richards \& Lockhart, 1996; Woods, 1996). An individual's beliefs are quite challenging to investigate due to their complex nature. Beliefs can be implicit and may be difficult to state explicitly (Van der Schaff, Stokking \& Verloop, 2008). Some teachers may not know what they believe in since their beliefs are subconscious (Donaghue, 2003). The complex nature of teachers' beliefs then necessitates appropriate methodology when they are studied.

The most common data elicitation techniques used in early studies on teachers' beliefs were questionnaires and interviews. Questionnaires are popular among researchers because they allow them to collect large amounts of data in a short period of time. However, questionnaires cannot provide a deep understanding of the complex beliefs a teacher holds (Borg, 2006). Interviews, on the other hand, allow participants to freely state what they believe and can allow researchers to capture more elaborate data. However, they have been criticized for containing the researcher's bias, especially within the interview questions. Furthermore, although the questions may guide the participants to talk freely during the interview, uncovering beliefs may still be difficult if the participants themselves are not aware of their own beliefs. Data gained from these instruments is usually criticized as being reported beliefs, not genuine beliefs (Borg, 2006; Phipps \& Borg, 2009).

\section{Repertory Grid Interview}


To overcome the criticism over questionnaire and interview tools to collect teachers' beliefs, this study employed the repertory grid interview, which encourages teachers to think critically and verbalize what they believe. The interview is based on George Kelley's Personal Construct Theory (1955). This theory posits that a person gives a specific meaning to a certain object according to their experience of the world. The meaning given to the object is considered as their belief about that certain object. In order to explore the belief, a respondent is required to make a comparison and contrast among other objects, which demands more critical thinking and justification. The procedure is believed to help tap into the deeper thought process of the participants. Due to the efficiency of this approach, we believe that employing the repertory grid interview will encourage teachers to think critically, leading to the revelation of their real beliefs.

In addition, we believe that drawing on one teacher's emic perspective by narrating their stories can provide rich data to uncover beliefs. Narrative stories can help reveal unique trajectories and beliefs that may be lost in other types of data collection. Therefore, this study aims to elicit teachers' beliefs through the use of repertory grid interview and to report the data through the lens of narrative inquiry. It is hoped that the combination of these two methods will allow researchers to better understand what teachers bring into their scoring practices.

\section{METHOD}

\section{A. Participants and Context}

Data from this study was taken from a larger study investigating teachers' beliefs about written feedback on students' writing tasks. The four types of written feedback included scoring procedure, focus of feedback, corrective feedback, and written commentary. In the larger study, ten participants (five native English-speaking teachers, and five Thai teachers) were interviewed.

In this paper, data from two native English teachers and two Thai teachers from the larger study was highlighted. These participants were selected because these four teachers mentioned scoring methods throughout all stages of their interviews. Data obtained from these participants could lead to the understanding of their beliefs concerning functions, challenges, and benefits in providing scores as writing feedback. They were given the pseudonyms John, David, Ubon, and Somsak. Both Thai teachers were teaching at a public university in northeastern Thailand, and the two native teachers were teaching at different universities in Bangkok. All of them had more than one year's experience in teaching writing at the university level.

\section{B. Data Collection}

Data collection was conducted in three stages: preparation stage, elicitation interview, and repertory grid interview.

1. Preparation Stage

In the preparation stage, a piece of argumentative writing task was selected from a fundamental English course offered at a university in Bangkok. It was written by a student whose English was in lower intermediate level. The writing was about whether gambling in Thailand should be legal, and the length of the composition was around 190 words. The reason for choosing this piece of writing was because it contained certain amount of errors, both grammatical and lexical. There would be several aspects that the teachers could focus on when they mark and provide feedback.

The participants were asked to freely evaluate the essay. Each participant received the same essay to mark and was allowed to grade, mark, score, and/or provide feedback. From observing the feedback that the participants used in evaluating the student's work, five types of scoring were revealed. The five types of scoring that were found among all participants were holistic scoring, analytic scoring, multiple trait scoring, point deducting, and commentary feedback.

2. Elicitation Interview

The purpose of this elicitation interview was to elicit possible "elements" and "constructs" that could be used in the repertory grid interview since in a repertory grid, meanings given to elements (types of scoring) are based on a bipolar construct. In general, elements and constructs used in a repertory grid interview can be taken from the literature or through elicitation from the participants. Since the aim of this study was to gain the real beliefs from the teachers without imposing any concepts or ideas upon them, we used the elicitation method. The elements were obtained from their feedback types they used in the preparation stage.

In the elicitation interview, the main purpose was to elicit the bipolar constructs to be used in the repertory grid interview e.g. clear or unclear. Specifically, the participants were asked to differentiate one element from the other two elements through triadic presentation. For example, they were given the triad of holistic scoring, analytic scoring, and multiple trait scoring. They also had to provide reasons for comparing and contrasting the elements or types of scoring. In this stage, the participants provided in-depth information of what they feel about and perceived each type of scoring. These constructs obtained from the elicitation interview were then used for the next stage of the interview.

3. Repertory Grid Interview

In the repertory grid interview, the elements and the constructs from the elicitation interview were used to conduct a more complex process of triadic comparison based on a bipolar construct and a rating scale. In this interview, the teachers were required to differentiate one type of scoring from the other two according to the bipolar constructs (clearunclear justification) which emerged from the earlier interview. At the same time, they had to provide a rating of 1 to 5 , 
$1=$ unclear justification, and $5=$ clear justification, to each type of feedback (element) according to the constructs (meaning), and they had to clarify their rating by using reasons or explanations for their judgment. For example, they might explain, "I think $A$ is different from $B$ and $C$. I rate $A$ as 1 , and $B$ and $C$ as 5 ." The rating task acts as a stimulus for the teachers to express their thoughts towards each type of scoring. It also helps the researchers to clearly see the participants' judgment of how each element relates to each construct.

\section{Data Analysis}

This study also employed narrative inquiry in reporting data from the repertory grid interview. According to Gibbs (2007), through their stories, the participants may be able to share and make sense of their experience. If we pay attention to people's stories, we may be able to gain insights into what is perceived as important to them as teachers, and "understand how they experience life" (Gibbs, 2007, p.58). Data from the interview was reported based on important themes that appeared in their talk during the repertory grid interview. Useful information from the other stages of the interview would also be narrated in the findings.

\section{RESULTS}

This section gives the description of four teachers' different views on using scores as the way to give feedback. The story of each teacher narrated during the repertory grid interview cast light on each individual's beliefs and experiences, as illustrated below.

\section{John}

The first story belongs to John, a teacher trainer and a researcher. He has a $\mathrm{PhD}$ in applied linguistics, and has a research interest in teachers' feedback. John did not seem to favor scoring, but preferred commentary feedback. His experience as a student was mentioned a lot during the interview. He said that throughout his learning period, receiving constructive feedback has helped inform him to become a systematic researcher and autonomous learner.

This one, I, as a PhD student, I like it when my supervisor writes this kind of comment because I can look at it, read it, put it down and think about it later on. (Excerpt 1)

In addition, through the interviews, John revealed how his experience shaped his belief about providing comments on students' work. His experience of what worked best for him influenced his belief about the practicality of his feedback and made him become a selective marker. He chose to give comments to specific points that would lead to writing improvement.

Usually, yes. I've tried... What I found in the past is that, if I read the first time and I mark as I go, I marked a lot. I marked everything and then it's very difficult for the student to see what's important and what's not very important. So I read it first once, and then I decide, I tried to decide what I think the students have made a lot of mistakes about. (Excerpt 2)

Because John strongly favored commentary feedback, he did not seem to believe in scoring. In the first interview, John explicitly stated that giving a score could actually distract the students instead of helping them to focus on how to improve their writing. To him, feedback should function as a thought-provoking response to students' work, because he would like students to be curious and try to learn autonomously, and according to John, a score does not seem to be helpful in promoting better writing when compared to commentary feedback.

I prefer not to give the score because I find that the score overwhelms the feedback. If they see the score, let just say I put eight out of ten here, they'll look at the score and say well, why did I only get eight and they won't look at the feedback for its value. If I don't put it there and then they come to see me and ask me what is this worth and I might say well, you lost the point here and you lost the point there. (Excerpt 3)

In the elicitation interview, John was asked to think critically and compare and contrast commentary feedback, holistic, and multiple trait scoring. John further clarified his point about his belief in commentary feedback. He seemed to be aware that commentary feedback could have both advantages and disadvantages for students. Although he thought it was useful, he also thought the students may not know how they should improve their writing. He also said that commentary feedback could potentially hinder students' understanding if it were too detailed and lengthy.

When comparing holistic scoring, multiple trait scoring, and commentary feedback, I think giving comments instead of scores is too complicated and detailed for students. If a student could understand all of that, it's good. But I think that for the student, there's too much here for it to be useful or for learning purposes. I mean, they wouldn't know where to begin. (Excerpt 4)

When John was asked to compare point deducting, holistic scoring, and commentary feedback in terms of consistency in marking, and judge each element on a Likert scale, he seemed to provide a clearer justification for using commentary feedback. He believed that this approach to feedback would be more consistent than using scoring rubrics. He provided reasons that having a clear objective in mind would help him to be consistent in his writing feedback.

So point deducting is 2 [less consistent]. And holistic scoring is 1 [not consistent]. I mean my content on my feedback wouldn't be consistent. I'm going to commentary feedback as 4 [rather consistent]. It's fairly consistent because what I'm going to do is pick out three things from everybody and comment on them. And my comments will be feedback for their development. (Excerpt 5) 
Although John believed that written commentary could help the students to improve their writing, he viewed it as a demanding task when he was asked to think more critically about its practicality. When he was asked about the practicality of providing each type of scoring (multiple trait scoring, point deducting, and written commentary), John said that providing written commentary required the most effort from teachers.

OK, I would say that written commentary is different from the other two [multiple trait scoring, point deducting]. It demands an incredible amount of effort, so I'm going to give written commentary as 1 [most demanding]. For multiple trait and point deducting, you don't have to scribble it out, so they are quite easy. So these two should be 4 [less demanding]. (Excerpt 6)

From the excerpts, it can be seen that John highlighted the importance of using feedback in learning by crafting useful comments that are not too complicated for the students, and as an evaluator he needs to be consistent and fair. In John's interview, it can be seen that he has revealed different angles of applying commentary feedback. He expressed concern about the "incredible amount of effort" involved in written commentary, while valuing its benefit in terms of being helpful to students' learning.

\section{David}

The second story was from another native English teacher called David. He has been teaching English in Southeast Asian countries including Thailand for more than 10 years. Prior to his current teaching job, David taught in high schools in Bangkok for eight years. He was responsible for teaching general English courses at bilingual schools. When he became a university teacher, David was given the opportunity to teach international program students.

David seemed to believe in applying an analytic scoring rubric as a criterion to help him assess a piece of student work. He also applied the rubric he used in his previous work for university students. He has used similar rubrics repeatedly, to the point that it has become automatic. David saw scoring rubrics as a way to provide his students clear explanations for the scores he assigns.

And I think it's more useful for the students in that it's essentially the rubric I found online and I've just simplified the terminology. It was made for high school students and I've just simplified it. I find the score that I would just pick out of my head is similar to the rubric anyway. If the students ask me why, this is something I can point to. (Excerpt 7)

In the preparation stage interview, when David marked the essay according to his preference, David assigned scores to the writing task. In contrast with John, David highlighted his preference for using a rubric in marking students' writing, as he noticed that a rubric could help both raters and learners to see specific scoring criteria. To him, having clear criteria was vital in making students understand where their scores came from.

OK. Well, I have my rubrics. There are four categories here. The first one is accuracy, and it usually relates to grammatical accuracy, syntax. And there's a format to check whether they follow the instructions, guideline. The organization, do they use things such as transition devices, do they have the beginning, middle, and end, and, cohesion and unity, again relates to sort of like transition. Does it make sense, is it logically flowing? Do they have pronoun consistency throughout? (Excerpt 8)

When he was asked about the use of written commentary, David mentioned that because his students are not very proficient, they may be confused and not be able to improve after seeing written comments.

I wouldn't use commentary feedback in my class, simply because most of the students in my class wouldn't be able to understand the comments. (Excerpt 9)

At the elicitation stage, David was asked to separate two elements from the group of three. He further provided reasons for using the analytic scoring rubric as a tool to allow meaningful feedback in multiple dimensions since the rubric provides clarification of each criterion in detail. Furthermore, having analytic scoring was unique because the way of assigning scores tends to be more consistent across students, especially with the low-achievers. He pointed out that using analytic scoring, as opposed to holistic scoring, makes it easier for the teacher to share with students about certain strengths and weaknesses.

At the last stage of repertory grid interview, David rated analytic scoring three out of five, as he was unsure of whether the method could help students to better understand the quality of their work.

With the writing grading rubric, I think it's very clear for them in analytic scoring as to what the problem was. However, I don't know how much it helps them. They understand when you explain to them. They don't know what to go on when they're writing the next time around. So it would be neutral, I'd give it a 3 [neutral in terms of helping the students to improve]. (Excerpt 10)

When David had to compare practicality among the three types of feedback, holistic scoring, analytic scoring, and written commentary, he clarified his point in using analytic scoring. Although he believed that analytic scoring could enhance learning and improvement, he also viewed that this type of scoring was somewhat demanding, when compared to holistic scoring and written commentary.

Holistic score, many teachers will simply read it and go, good or bad, and give a score within two to three minutes. So holistic scoring is 5 [least demanding]. Analytic scoring, I would say, once you familiarize yourself with the descriptors, you have to go back and look at each descriptor sometimes, so it's a 3, somewhere in the middle. And for written commentary, not giving a score, I'd give it a 4 [less demanding] because you do have to read carefully. (Extract 11) 
The extracts from the interviews showed David's preference for analytic scoring. He emphasized consistency in scoring and marking, and being accurate. He also mentioned his experience in using analytic scoring rubrics, and that it made him a confident rater. When he had to compare it with other types of scoring, David critically considered this type of scoring as he seemed to think about both the pros and cons of this approach. He carefully thought about learners' factors as he mentioned his uncertainty in whether analytic scoring could promote better writing in the long term. However, considering the fact that teachers like him might have a large amount of writing to mark, David added the issue of practicality in selecting the approach he would use in case he had a different number of writing tasks to deal with.

\section{$\underline{\text { Ubon }}$}

Ubon has been teaching English in a university in northeastern Thailand for more than seven years. She is responsible for teaching general English. She mentioned that she did not have a lot of experience in teaching English, since she specialized in teaching Thai language to foreigners. Despite having taught in the university for more than five years, Ubon often referred to herself as an inexperienced teacher. This embedded belief appeared to affect her way of giving corrective feedback, as seen in the following excerpt:

Well, actually I haven't thought of giving scores. If I was told to give scores, then I probably would give this student scores. (Excerpt 12)

In the preparation stage, when she was asked to freely mark a student essay, she asked for more clarification of the writing. She simply gave written comment, without giving scores. Since she perceived herself as an inexperienced teacher, she said that she did not have the courage to provide scores. She mentioned that she needed guidance to follow. Thus, she chose to provide only commentary feedback.

When participating in the second stage of repertory grid interview, she clarified her cautious stance in using commentary feedback when compared to other elements. At this stage, she chose analytic and multiple trait scoring as her preferred methods of scoring because both methods allowed her to be objective. Compared to David, who used analytic scoring with confidence and employed it to aid students' learning, Ubon saw analytic and multiple trait scoring as a way to keep teachers on a consistent marking track and as a way to provide specific guidance for her students to improve their writing. The data from this stage revealed the beliefs of Ubon as an inexperienced teacher who felt more confident with the guidance from a rubric.

Sometimes when you give commentary feedback, the teacher may overlook some points and tend to emphasize certain points. It gives feedback as a whole, so the teacher may neglect the point the students already did well in their writing. If you give analytic or multiple trait scoring, the teacher will be more specific on what they expect from the students. (Excerpt 13)

Her belief about using a rubric as a guideline became clearer when participating in the third stage of repertory grid writing. When asked to rate the elements, she started giving reasons behind her choices. Ubon explained that rubrics might be useful for a teacher, but did not seem to be beneficial for students since they may not know exactly what to modify in their writing in order to improve their quality. However, she took students' improvement into account when rating for written commentary, which she rated five. Ubon always mentioned the aspect of student's writing improvement when rating in the last stage. It was because she considered her students as having a low level of English proficiency, so any scoring methods that make them understand clearly what they have done wrong and how they could improve were preferred by Ubon.

Comparing between analytic scoring, multiple trait scoring, and written commentary, I think written commentary can lead to improvement that I give a rating of 5 [helps students to improve]. I think the students will read it and feel like the teacher is talking to him or her directly and they will go back and look at what they have done wrong. Analytic scoring and multiple trait scoring, they have criteria and have clear rubric, but the students may not know how they can use that rubric to revise their writing, so I give these two types a 3 [neutral in terms of helping the students to improve]. (Excerpt 14)

Ubon further explained that her rating of five for written commentary as the way to help students learn from feedback was also dependent upon her teaching context. When there are a lot of students submitting their writing assignments at the same time, and they also expect to receive feedback from their teachers, the issue of time also became vital in her decision to use a certain marking method.

In terms of practicality, holistic scoring will definitely be the fastest. If we have 40 papers to mark, it can be done very quickly. Analytic scoring will also take less time to do, so I give holistic scoring and analytic scoring a 5 [least demanding]. Although holistic scoring does not provide any descriptors, I believe that the descriptors are already embedded in teachers' mind. But for written commentary, it is the most demanding because the teachers need careful consideration. It will take a large amount of time. (Excerpt 15)

The interview data showed that Ubon preferred to start with some guidelines, as she considered herself an inexperienced teacher. Therefore, she preferred using rubrics as the guidelines for her evaluation of students' writing. But later on, it seemed that she preferred written commentary because she was concerned more about learners' improvement. She believed that communicating with the students through her feedback would help them to improve.

\section{Somsak}


Somsak is a part-time teacher at a university in northeastern Thailand. He had been teaching at the university for almost four years at the time of the study. Similar to Ubon, he is responsible for teaching general English courses for first- and second-year students, whose proficiency levels were considered beginner to lower-intermediate.

In the preparation stage, Somsak explained his method of using negative scoring as his approach. Somsak viewed this method as a useful tool to lead the students to language accuracy. In addition, Somsak believed that Thai teachers were not as fluent as native-speaker teachers. He felt that focusing on accuracy, which is more objective, would be less risky for him.

In practice, I think my experience of being a teacher, I deduct 0.25 to 0.5 in students' work as I feel that it suits the nature of Thai teachers. I mean, we always focus on grammar and I feel more confident when deduct points on grammatical errors. So when I have to mark the essay, I would use this as it will have less effect on me as a teacher. (Excerpt 16)

Somsak clarified his belief about grammatical correctness in the later interview. At this stage, he was asked to differentiate among analytic scoring, multiple trait scoring, and point deducting. He became aware that the method that he kept using was not the answer for overall writing components. He started questioning his own practice since he could see that focusing only on grammar when deducting from students' scores could not lead to future writing improvement.

I would say that analytic scoring, and multiple trait scoring can be grouped together, but point deducting is different. Analytic scoring and multiple trait scoring give overall elements in writing because they cover the areas of unity, accuracy and organization. When teachers use clear criteria like that, they can be sure that they have covered all aspects of writing which students should be aware of. For point deducting, however, it focuses only on the grammatical aspect. When I think about point deduction that I have done so far, I only focus on deducting score when my students write ungrammatical sentences. It did not cover all aspects like analytic scoring and multiple trait scoring. (Excerpt 17)

During the elicitation interview, Somsak stressed his awareness of the limitations of point deducting, as he rated the method at three. For him, point deduction only tells students their weaknesses in writing rather than showing them their strengths. He said that giving feedback should be multifaceted because students should know several components of writing in order to be effective writers.

In terms of writing improvement, commentary feedback gives a clear comment for most aspects of writing. It also depends on each teacher, whether they tell the students what they expect. But for point deducting, I give this a 3 [neutral in terms of helping the students to improve] because it only tells the students their weakness, not their strength. When the students receive this type of scoring, they'll probably be curious about which point they need to improve. (Excerpt 18)

Not only did students' writing improvement become prominent in his decision to choose certain corrective feedback; practicality was another criterion in his mind when having to explain the differences of each approach when rating.

Written commentary is the most difficult among the three types of feedback. It requires time to read, so I think it's the most demanding. For holistic scoring and multiple trait scoring, you have some guidelines to look at from the descriptors, so they are easier. So I would say these two are the least demanding. (Excerpt 19)

Data from the interviews showed that Somsak believed in providing a single score by deducting marks for grammatical mistakes from students' writing. He tried to focus on multiple aspects of grammar specific to the piece of writing as to have confidence in his feedback. However, when he thought critically about other factors such as students' learning, he seemed to prefer commentary as it was more helpful to provide guidance for improvement. When the the issue of practicality was involved, he seemed to believe that holistic and multiple trait scoring were rather helpful for teachers who have a lot of writing pieces to evaluate.

\section{DISCUSSION}

The findings suggest that native and non-native teachers have shared beliefs about scoring feedback. The themes that concomitantly appeared throughout different stages of the repertory grid interviews were students' learning and improvement. Every participant felt that the ultimate goal of giving feedback is to promote learning (Hyland \& Hyland, 2006), and this strong belief about the role of feedback has guided their decisions in selecting appropriate approaches of giving feedback. Even though the participants' preferred feedback types seemed to vary, they all supplied the same underlying reasons for using them. The common core of beliefs about feedback seemed to be rooted in the roles that feedback plays in learning, while the approaches used or types of feedback employed seemed to be the result of interplay among different factors. These reflect the complex construct of teachers' beliefs. The participants' deep thought processes elicited from the triadic comparison of different elements of feedback types revealed that they went through intricate steps in deciding what to do. For instance, giving scores seemed to emerge not solely because the method is likely to be simple. It, however, is derived from the teachers' intention to draw students' attention to learning, which starts by providing an overall level of performance in a single number in order not to immediately overwhelm them with complicated details. Interestingly, this similar belief about promoting learning appeared in the reasons of the participants who stated that they believed in commentary feedback. They share the common goal of suggesting ways to improve students' learning and writing performance. This seemed to be the reason why those who supported the use of commentary feedback were worried that detailed feedback may lead to a negative effect when compared to other approaches. 
This intricate construct of teachers' beliefs makes it difficult to judge whether we should eradicate holistic scoring as suggested by Hamp-Lyons (2016a, 2016b), as the feedback types seemed to be the tip of the iceberg of teachers' beliefs Beliefs are personal constructs that play important roles in a teacher's decision to do different things in and outside classes (Kelly, 1955). The narrative stories that native and non-native teachers in this study revealed through the repertory grid interviews suggested that the ways that they employed different feedback types to assess students' writing seemed to involve the interplay of different factors. The major ones include attempts to balance issues (learning and practicality), objectivity of the feedback, personal experience as teachers and learners, and teachers' confidence.

\section{A. Balancing between Learning and Practicality}

From the findings, it becomes apparent that teachers who participated in this study believe that the major role of providing feedback is to enhance students' learning, and writing improvement. With their focus on helping the students, the teachers tried to provide feedback that allows students to clearly see the points they need to improve. They seemed to prefer written commentary as the feedback approach which can be used to provide information about what the teachers think about students' writing. Teachers use this method to respond to students' work rather than evaluating it (Hyland, 2003). Therefore, the teachers could pinpoint multiple aspects that need to be improved, and let the students think and be able to revise their writing by themselves. This is in accord with the idea of Hamp-Lyons (2016a, 2016b), who urged teachers to focus on the complex nature of writing, and not only on a single score.

However, when the issue of practicality comes into consideration, teachers may not be able to conform to their beliefs in providing commentary feedback. Previous literature on writing feedback has found that teachers seem to struggle to balance the aim of helping the students to learn, and practical constraints (Ferris, 2014; Junqueira \& Payant, 2015; Lee, 2009; Phipps \& Borg, 2009). Two issues of practicality that come into play when the teachers make decisions to provide feedback involve students and the teachers themselves. For students, the practicality issues relate to their ability, and for teachers, the issues relate to their time and effort in providing feedback. Our study found the proficiency level of the students is one of the major factors. Because the teachers are aware of their students' proficiency level, they are worried that providing commentary feedback may be too complicated and could simply confuse the students. Concerned that learning may not take place if the students cannot understand teachers' feedback, the teachers may try to avoid giving commentary feedback. Instead, they may use simpler feedback approaches such as scoring. What this revealed is an incongruence between teachers' beliefs and practice.

In addition, the amount of effort needed in providing feedback can be seen as a factor that prevents teachers from acting in line with their beliefs. The workload makes them unable to focus on individual writing problems. In addition, classes which are very big (more than 30 students) encourage teachers to select methods that are the most workable for them. As seen from the findings, the teachers seemed to view holistic scoring as the easiest method, even though they believe that commentary feedback is more helpful for the students. Therefore, providing a single score through holistic scoring is still employed by the teachers, even though its effects contradict their beliefs.

\section{B. Enhancing Objectivity of Feedback}

The findings revealed teachers' beliefs and concerns about reliability and consistency of their feedback. The teachers attempted to provide clear and understandable feedback, and they tried to use scoring rubrics that provide clear and understandable descriptors. From doing this, they can maintain consistency when marking a lot of essays at the same time. This may be why teachers mentioned analytic scoring and multiple trait scoring as methods that could provide clear guidance. With the explicit descriptors, teachers can give scores and feedback that match the content they have taught, and can enhance the objectivity of their feedback (Hyland, 2003).

\section{Influence of Prior Experiences}

Experience as both learners and teachers also reinforces teachers' beliefs about effective feedback and guide their decisions. Some teachers had direct positive experience that commentary feedback had worked well for them, and seemed to believe that providing commentary would also work for their students. This supports the idea of Hyland and Hyland (2006) and Lee (2008) that scoring practices may reflect teachers' beliefs about learning and language gained from previous knowledge. Some teachers experienced commentary feedback in their writing while they were learners. Others did not like to have their errors pointed out, as it was discouraging and demotivating to receive papers awash in red ink. For this reason, they tended to avoid using the same approach when they became teachers themselves.

Experience of what works best as a teacher could affect their feedback practices. The use of scoring rubrics can be an effective approach to tell students how well they have performed in a writing task (East \& Cushing, 2016), and it could draw students' attention to teachers' feedback. Some students even compare their own score with others in the same class. Knowing that providing scores has appeared successful for them as a teacher, they seem to apply the scoring approach as their method of providing feedback.

\section{Lacking Confidence When Giving Feedback}

Interestingly, individual confidence can affect teachers' beliefs when deciding to use particular types of feedback. In the present study, non-native teachers mentioned a lack of confidence when providing feedback to students, similar to the study by Junqueira and Payant (2015). For them, the point-deducting type of scoring for language accuracy 
(grammatical points) seemed to work best, as they gave teachers more concrete guidelines to refer to when providing feedback, and thus they felt more confident in marking. Their lack of confidence may be related to not having an educational or linguistics background. Therefore, they prefer to play safe when providing feedback. This self-doubt led them to select an approach that has specific guidelines to follow when marking students' writing, and to focus on localized errors, which are more concrete than global errors. Even though they believed that students should be told what they have done wrong in all aspects of writing in order to improve their learning and writing, the teachers' lack of confidence seemed to prevent them from going beyond discrete grammar points in their feedback. They did what they felt certain of, rather than risking themselves by focusing on the use of language when giving feedback. While this may set the non-native teachers apart from their native counterparts, their approach in providing feedback could be what students are able to manage, since the students of the participants are largely local Thais.

\section{CONCLUSION}

This study attempted to investigate teachers' beliefs about their scoring feedback through the use of repertory grid interview. The findings revealed that teachers' beliefs were complex, and that factors such as students' learning, teachers' practical considerations, and teachers' personal experience could reinforce their beliefs. It is impossible to consider only one factor without paying attention to the other factors. Teachers' feedback in practice may not reflect their innermost beliefs, and in turn teachers' beliefs may not be reflected in their practice.

Therefore, the repertory grid interview allowed us to tap into teachers' beliefs as it encouraged them to think more critically, and allowed us to see the dimensions that could influence their beliefs. Beliefs about scoring show that teachers employ feedback chiefly as a tool to aid student learning. Although other people may see scoring as only a single number, for teachers, that single score may have many underlying rationales since they have considered several factors, such as students' learning and practicality, in order to reach their decisions in assigning scores. While scoring may seem to be less useful in enhancing students' writing development, it may be useful for teachers as an attentiongetter to lead students to their additional comments which can enhance learning.

\section{REFERENCES}

[1] Basturkmen, H., S. Loewen \& R. Ellis. (2004). Teachers' stated beliefs about incidental focus on form and their classroom practices. Applied Linguistics 25.2, 243-272. https://doi.org/10.1093/applin/25.2.243.

[2] Borg, S. (1999). Studying teacher cognition in second language grammar teaching. System 27.1, 19-31. https://doi.org/10.1016/S0346-251X (98)00047-5.

[3] Borg, S. (2006). Teacher cognition and language education: Research and practice. London: Continuum.

[4] Donaghue, H. (2003). An instrument to elicit teachers' beliefs and assumptions. ELT Journal 57.4, 344-360. https://doi.org/10.1093/elt/57.4.344.

[5] East, M. \& S. Cushing. (2016). Innovation in rubric use: Exploring different dimensions. Assessing Writing 30, 1-2. https://doi.org/10.1016/j.asw.2016.09.001.

[6] Ferris, D. R. (2014). Responding to student writing: Teachers' philosophies and practices. Assessing Writing 19 , 6-23. https://doi.org/10.1016/j.asw.2013.09.004.

[7] Ghalib, T. K. \& A. A. Al-Hattami. (2015). Holistic versus analytic Evaluation of EFL writing: A case study. English Language Teaching 8.7, 225-236. http://dx.doi.org/10.5539/elt.v8n7p225.

[8] Graham, G. (2007). Analyzing qualitative data. London: Sage.

[9] Hamp-Lyons, L. (2003). Writing teachers as assessors of writing. In Kroll, B (ed.), Exploring the dynamics of second language writing. Cambridge: Cambridge University Press, 162-189.

[10] Hamp-Lyons, L. (2016). Farewell to holistic scoring. Assessing Writing 29, A1-A2. https://doi.org/10.1016/j.asw.2015.12.002.

[11] Hamp-Lyons, L. (2016). Farewell to holistic scoring. Part Two: Why build a house with only one brick? Assessing Writing 29, A1-A5. https://doi.org/10.1016/j.asw.2016.06.006.

[12] Hyland, K. \& F. Hyland. (2006). Feedback in second language writing: Contexts and issues. New York: Cambridge university press.

[13] Hyland, K. (2003). Second language writing. Cambridge: Cambridge University Press.

[14] Junqueira, L. \& C. Payant. (2015). "I just want to do it right, but it's so hard": A novice teacher's written feedback beliefs and practices. Journal of Second Language Writing 27, 19-36. https://doi.org/10.1016/j.jslw.2014.11.001.

[15] Kelly, G. (1955). Principles of personal construct psychology. New York: Norton.

[16] Lee, I. (2008). Understanding teachers' written feedback practices in Hong Kong secondary classrooms. Journal of Second Language Writing 17.2, 69-85. https://doi.org/10.1016/j.jslw.2007.10.001.

[17] Lee, I. (2009). Ten mismatches between teachers' beliefs and written feedback practice. ELT Journal 63.1, $13-22$. https://doi.org/10.1093/elt/ccn010.

[18] Mahfoodh, M. \& Pandian, A. (2011). A qualitative case study of EFL students' affective reactions to and perceptions of their teachers' written feedback. English Language Teaching 4.3, 14-25. http://dx.doi.org/10.5539/elt.v4n3p14.

[19] Min, H. T. (2013). A case study of an EFL writing teacher's belief and practice about written feedback. System 41.3, 625-638.

[20] Pajares, M.F. (1992). Teachers' belief and educational research: clearing up a messy construct. Review of Educational Research 62.4, 307-331. http://dx.doi.org/10.3102/00346543062003307.

[21] Phipps, S. \& S. Borg. (2009). Exploring Tension between teacher's grammar teaching beliefs and practices. System 37.3, 380390. https://doi.org/10.1016/j.system.2009.03.002. 
[22] Richards, J. C. \& C. Lockhart. (1994). Reflective teaching in second language classrooms. Cambridge: Cambridge University Press.

[23] Van der Schaaf, M. F., K. M. Stokking \& N. Verloop. (2008). Teacher beliefs and teacher behavior in portfolio assessment. Teaching and Teacher Education 24.7, 1691-1704. https://doi.org/10.1016/j.tate.2008.02.021.

[24] Weigle, S. C. (2002). Assessing writing. Cambridge: Cambridge University Press.

[25] Woods, D. (1996). Teacher cognition in language teaching: Beliefs, decision-making, and classroom practice. New York: Cambridge University Press.

Parinda Jantori is a PhD candidate at School of Liberal Arts, King Mongkut's University of Technology Thonburi. She obtained her Master of Arts in English from Chulalongkorn University. She is currently working on research into teacher's belief.

Saowaluck Tepsuriwong, PhD, is an Assistant Professor and Head of the Language Studies department at the School of Liberal Arts, King Mongkut's University of Technology Thonburi. Her research interests include language learning and teaching pedagogy, materials design and communication strategies.

Pornapit Darasawang, PhD, is Vice President for Internationalisation at King Mongkut's University of Technology Thonburi, Thailand and an associate professor in the Department of Languages, School of Liberal Arts. She obtained a PhD in TESOL from the University of Edinburgh. Her research interests lie in learner autonomy, self-access learning, and learner training. 